\section{Gonçalves Cruz (1872 - 1917) *}

\author{
Luiz Fernando Ferreira **
}

As verdadeiras vossas são tamanhas

Que excedem as sonhadas fabulosas

Que excedem Rodamonte e o vão Rugeiro

E Orlando, inda que fora verdadeiro

\section{dos Lusíadas}

Oswaldo nasceu em São Luiz do Paraitinga, São Paulo, em 5 de agosto de 1872. A cidade tem nome de rei. De rei que foi santo, que comandou uma cruzada; guerreiro; que punha cinzas na comida. Santo-Herói.

O clima do país é o de final de Império. A figura dominante, é de longe, Pedro II. Gilberto Freire em "Perfil de Euclides e outros perfis" assim o descreve, no seu estilo irreverente:

- "Entre livros que no seu palácio recebia, como Pedro I às mulheres: antes dos grandes do Império. Pelo menos foi o que aconteceu ao pastor protestante norte-americano que lhe levou de presente, num simples tilburi, um dicionário de Webster, Mosses From an Old Manse de Howtorne e um Hyperion de Longfellow: foi recebido antes dos titulares, dos conselheiros, dos diplomatas 'en grande tenue'. .. No meio dos livros, Pedro II perdera de vista o Brasil: um Brasil que o queria não de cartola mas de coroa; $e$ marcial, paternal, litúrgico, em relevos de ação. Um Brasil que o queria mais para o ver de cetro, reinando a cavalo, como um São Jorge de verdade, do que para lhe ouvir os discursos e as frases de censor moral, de Marco Aurélio mediocre, de literato de terceira ordem... Creio que é do grande romântico alemão dos nossos dias - brasileiro, aliás, por um dos costados: Thomas Mann - o conceito de que só há cultura viva quando se verifica o jogo heróico dos contrários. Conceito bem Wagneriano. Foi o que mais faltou à politica do Brasil de Pedro II: o jogo heróico dos contrários. Sua música foi a de Verdi, melodiosa e maciamente burguesa. Cinzenta. Cor-de-rosa".

0 ambiente intelectual da época também tem a marca do Imperador. Às vezes impiedoso, às vezes errando. Mas aqui ele decide. Seguro. De casaca, cartola, e calça branca. Burguês é verdade; mas aprendeu a mandar - de menino.

Jamais faltava aos concursos de professor catedrático da Escola de Medicina, ou do Colégio Pedro II, nem às reuniôes do Instituto Histórico e Geográfico. Sonhou um laboCadernos de Saúde Pública, R.J., 4(3):507-517,out/dez, 1987
* Discurso proferido em Curiti. ba, em novembro de 1987.

* Vice-Presidente de Recursos Humanos da FIOCRUZ. 
ratório de Fisiologia em pleno verde tropical. Era membro da Academia de Ciências de Paris. Seria mestre-escola, assim o declarou, se não tivesse nascido rei.

Freire é impiedoso na sua descrição. Mas também é profundamente significativo que quando o major Solon, trazido de volta à cena recentemente, como pai de Ana de Assis, entrega a Pedro a ordem de saída do país, a mando dos grandes da República, o faz constrangido. Envergonhado talvez fosse a melhor palavra.

O país tem as suas especificidades. A sua cor própria. A Europa nos trópicos, é contraditória, é lúdica, é gostosa. Melhor que a de lá.

O Padre Alencar é senador do Império, respeitabilís. simo, grande político . . mas que tem mulher e filhos. $\dot{E}$ pai de José de Alencar. E tudo isso a portas escancaradas, às claras.

Império Tupiniquim, onde reinaram princesas austríacas, e também das duas Sicilias. Todas de fino trato e fina educação. Onde três ou quatro pessoas, sabiam o Fenício, o Hebraico e o Grego. Onde alguns sabiam Francês, Alemão e Inglês. Muita gente sabia Latim; todo o clero e mais alguns. Onde havia Observatório Astronômico, Museu de História Natural, o padre José Maurício e Carlos Gomes. Corte burguesa, de chinelos. Um Imperador louro, de olhos azuis, Habsburgo, reinando num país de mulatos, índios e negros - que o amavam.

Havia também o padre Diogo Feijó que além de raposa em política, escreveu pela primeira vez em terras tropicais um tratado sobre a filosofia de Emanuel Kant. Além dos sábios estrangeiros que por aqui passaram. $E$ os que por aqui ficaram. Como o velho Lund; como Fritz Müller protegido da princesa - o da lei biogenética fundamental. Fritz Müller de Desterro, como Hoeckel de Berlim, e como Huxley de Londres. Recebe convites da Europa:

- Uma cátedra em Berlim?

- Não, prefiro ensinar os meninos daqui. Gosto de andar descalço.

E um Machado, mulato, epiléptico e autodidata, mas gênio - sem dúvida. Universidade não havia. Mas tudo que uma universidade faz, aqui se fazia; nas escolas profissio. nais, ou muitas vezes em casa. A fisiologia no Brasil, nasceu no porão da casa dos Ozório de Almeida.

Império de barões feulais, senhores de muitas terras e muitas mulheres - alguns de fato; outros de vontade. Da Europa, vem o brilho da "belle èpoque" as atrizes do Teatro Lírico e do São Pedro de Alcantara - gordinhas, sucesso absoluto.

Todos sonham em ser Vitor-Hugo. Dos Estados Unidos não se fala; ainda vai chegar. França e Alemanha ponti- 
ficam. Quem melhora um pouco na vida, procura uma "Frau" para educar os filhos. Compras pelo "Collie-Posteau".

Com a República nada muda. Mesmo porque o século só vai acabar em 1914.

Fica tudo como d'antes no quartel d'Abrantes.

Os Gonçalves Cruz, vêm da Freguesia de $\mathrm{S}$. Tiago de Mourilha, Termo de Monte Alegre - Arcebispado de Braga. Lusos portanto, com a sua percentagem maior ou menor de sangue mouro. Afinal de contas, foram vários séculos, de bélico e amoroso convívio.

Referências seguras, os apresentam em 1767 estabelecidos como comerciantes de tecidos em Guaratinguetá. Daí a familia se transfere para o Rio de Janeiro, onde o Dr. Bendo Gonçalves Cruz se formou em medicina. Recémcasado, vai "fazer a clínica" em São Luis do Paraitinga. Lá, nasceu Oswaldo.

Uma agradável viagem de fim-de-semana, me levou a mais ou menos um ano atrás, em companhia de minha mulher, do Luiz, e do Paulo Gadelha a São Luis.

A praça com a igreja, o velho casarão assobradado onde nos hospedamos, as construções de época bem conservadas, a casa onde nasceu Oswaldo, hoje transformada em museu, nos permitiram imaginar o que seria a vida nessa cidade, no fim do século passado. E também o que seria aí, a vida de um médico. Não seria vida abastada por certo. Seria lírica, romântica - pastoral eu diria. Não nos alongaremos. Penso que todos têm essas imagens dentro de si. Fantasias, impreg. nadas de individualidade. São lindas, não vamos procurar objetivá-las, com medo de alterar o traço ou manchar a cor. São as de cada um.

Em 1877 a família vem para o Rio de Janeiro. Oswaldo tem portanto cinco anos. Ainda faltam doze anos para a República.

Sobre seus dados biográficos se referiram Ezequiel Dias, Belizário Pena, Henrique Aragão, Phocion Serpa, Gastão Pereira da Silva, Olímpio da Fonseca, entre outros. Além da célebre conferência de Rui Barbosa, no Teatro Municipal, em 1917. Não nos esqueçamos também das inestimáveis publicações de Edgar Cerqueira Falcão; foi médico, fotógrafo, historiador, e de muitas outras prendas. $\mathrm{O}$ que ele fazia, era sempre bem feito.

A fase heróica, dos grandes feitos, se realiza no roldão de poucos anos. Quinze, não mais. Houve outro que fez tudo em três anos, é verdade, mas esse, era muito Especial. 
$O$ resto é uma infância e juventude, em nada diferente de outras infâncias e juventudes, de sua classe social e sua época.

Menino dócil, bem educado, cumpridor de suas obrigações. Trata os adultos com educação e respeito. Phocion Serpa em "A vida gloriosa de Oswaldo Cruz" escrito para a juventude, e tão ao sabor da época assim o descreve: ". . . o pequeno Oswaldo era tão dócil, tão meigo e carinhoso, que para feri-lo fundamente, bastava que seus pais the recusassem à noite a hora em que ele se recolhia, aquele beijo costumeiro das despedidas".

Adulto, sabe mandar. Autoritário. Passional. Wagneriano. Mas vai continuar também, meigo e carinhoso.

Em janeiro de 1908 já consagrado, escreve à esposa:

\section{"Minha adorada Miloquinha}

Assim que levantei-me hoje, a primeira coisa que fiz foi dirigir-me ao telégrafo, para enviar-te minhas melhores caricias, traduzindo minha gratidão pela felicidade duradoura com que me suavisastes a vida consentindo em ser minha companheira e meu anjo da guarda..."

De Paris em 1907 escreve :

"Minha querida Miloquinha

Aqui chegado procurei imediatamente dar cumprimento as tuas incumbencias. Fui a Igreja de N. S. das Vitórias para pagar tua promessa ..."

São várias e várias cartas, todas do mesmo teor.

O Luís prometeu preparar para publicação. Estamos esperando.

O Colégio Laure e depois o São Pedro de Alcantara. Aluno estudioso. De acordo com a regulamentação da épo$\mathrm{ca}$, exames finais no Pedro II. Provas públicas. Todo mundo ia assistir. Um suplício para os candidatos. Muitas vezes ouvi meu pai contar o que eram esses exames.

Aos 14 anos, a Faculdade de Medicina do Rio de Janeiro. Nada de excepcional para a época. Desse tempo, e durante toda a vida, a marca forte da personalidade do pai. Presença constante em sua vida, antes e depois de morto.

Médico formado, o casamento em janeiro de 1883 com Emília da Fonseca; os filhos. Em 1896 parte com a fa. mília para a Europa. Paris - anos de estudo. O fascínio por Pasteur. O qu'mico que revolucionou a Medicina; o filho do curtidor de Arbois, o menino pobre da província, cuja vida foi dedicada ao bem da humanidade. Que estudante em 
Paris escreveu para casa: "Se eu pudesse ainda uma vez sentir o cheiro do cortume encontraria forças, para os novos embates".

Também alguns anos antes o nosso Imperador ficara fascinado por Pasteur. Trocaram correspondência, e foram grandes as doações feitas por Pedro para a fundação do Instituto Pasteur. Seu busto lá está até hoje, em lugar de honra. Oswaldo iria se beneficiar dessas doações. Pasteur - no aspecto físico, nos gestos, na postura, na persistência com que dedicava ao trabalho no laboratório, ou à conquista da mulher que escolheu para sua esposa - tinha muito de sacerdote de um novo culto.

O mestre já havia falecido, mas os discípulos de primeira hora, estavam no apogeu. Emile Roux é o diretor. Metchnikoff deslumbra o mundo científico. E é com esse russo, comedor de coalhada búlgara, que vai se ligar por uma grande amizade. Recebe dele convite para irem juntos para Rússia. Pesquisas científicas fascinantes. Oswaldo recusa, mas se sente valorizado.

Estudos de Toxicologia com Ogier e Vibert. Higiene e Medicina Legal constituindo a assim chamada Medicina Pública. Era a época. Ainda conheci professores que acumulavam as duas cátedras. Às vezes uma na Escola de Medi. cina outra na de Direito.

A Europa que ele vai encontrar é Vitoriana; Imperial. Moralista demais por fora, escorregando muito por baixo do pano. Mas seduzindo a todos, moralistas ou devassos.

O príncipe de Gales, que passa a maior parte do seu tempo em Paris, é o 'modelo da boêmia elegante, da "jeuneusse dorée".

Um dia, tendo encontrado Sherlock Holmes empenhado em solucionar um novo mistério, o Dr. Watson the disse:

- Meu caro amigo, você tinha jurado nunca mais se envolver em novo caso.

Ao que Holmes respondeu:

- Mas veja Watson. Se fosse o Czar de todas as Rússias, eu diria não.Se fosse o Sultão da Turquia, eu diria não. Se fosse o Sr. Primeiro Ministro, eu também diria não. Ao Kaiser, ao primeiro Lord do Almirantado, ao Arcebispo de Canterbury, ao Papa enfim, a todos eles, eu diria não.

Mas foi Ela (leia-se a Rainha Vitória), e a Ela não se diz não.

Aliás, ninguém como ela, investiu tantos recursos para pesquisa em Medicina Tropical.

É a Europa "fin de siècle", "belle époque". 1914 ain. da está longe. Na medicina, a revolução pastoriana, passado o período heróico se consolida com largos avanços. Os " $c a$ - 
çadores de micróbios" são os heróis do momento. Trabalhase com paixão, pelo bem da humanidade, com gestos litúrgicos. Existe um Papa, seus cardeais e sacerdotes; existe fé, dogmas, cultos, sacramentos e iniciação. Embora tudo isso seja sempre religiosamente negado. Em nome da razão, das luzes.

Tudo isso Oswaldo Cruz vai trazer da Europa. Vai escrever no seu Ex-libris: "Fé eterna na ciência". E um dia dirá do seu castelo mourisco: "O templo da ciência, deve ser faustoso".

Afinal de contas o ritual é indispensável.

Volta ao Brasil em 1899. É um iniciado. Tem uma missão e fôlego para cumpri-la. Está escrito: "Teremos um Institu to Pasteur do lado de baixo do Equador".

Mas é também mundano, vaidoso - é um europeu usa bigodes à Kaiser.

Ezequiel Dias o retrata nessa época: "Todos os dias, mais ou menos a mesma hora, quando os bondes desciam aninhados para o centro da cidade, era certo encontrar-se num dos carros de Largo dos Leōes, aquele homem aparentemente robusto, de estatura meã, sobrecasaca preta, cartola muito alta e gravata branca, à Principe de Gales". ra meã.

Cartola especial, muito alta, para compensar a estatu-

Foi Eduardo Marques quem me levou pela primeira vez a Manguinhos, também ele, um homem à belle époque, elegante, boêmı, erudito. Falando francès com a perfeição de um parisiense. Em 1907, veio para Manguinhos, fazer a sua tese de doutoramento - Das neurofibrillas e seu desenvolvimento. Conheceu o mestre. Viria a se tornar seu contraparente quando seu sobrinho Eduardo Tinoco se casou com a irmã de meu pai. Menino ainda fui com ele várias vezes ao Instituto. E ouvia embevecido as histórias que me contava de Oswaldo e das pesquisas que ali se faziam. Tinha paciência com o jovem neófito.

Creio que foi ele, e os caçadores de micróbios de Paul Kruif que despertaram a minha vocação.

Em uma geração antes da minha, Gastão Pereira da Silva assim se expressa: a figura singular de Oswaldo Cruz foi no entanto uma das mais fortes impressões da minha infância. Quando menino ouvia falar dele, como se fala de um Deus, ou do Diabu ao mesmo tempo. Uns o defendiam, outros o atacavam.

Me relatou Jeth Jansen, que certa vez ainda menino, acompanhava montado num pônei, seu pai, oficial do exército, que exercitava um pelotão de cavalaria. Lá para os lados de Manguinhos. Em certo momento, a uma ordem de comando, o pelotão estanca em cerimoniosa saudação mi- 
litar. Vendo que era um civil que passava diante deles a cavalo, ficou intrigado.

Mais tarde perguntou ao pai, quem era esse homen e porque fazia jus a tal honraria:

- Esse homem é um sábio, respondeu-lhe o pai. Se chama Oswaldo Cruz.

Foi mitifica do em vida. Como Einstein.

Em 1912, a Academia de Letras. Por quê? não importa; porque é Oswaldo; vacila mas aceita - fardão e espada.

Em 1899 surge a Peste no Porto de Santos. Pede-se socorro à Europa. Bons clínicos por certo aqui haviam. Da melhor cepa, e da melhor tradição. Francisco de Castro, era o Divino Mestre, que além de sabedoria, possuía um Perfil Nazareno. Morreu mártir, no exercício do ofício. Ao se debruçar sobre um paciente para o exame cuidadoso, se contamina: Pneumonia pestosa.

Pouco tempo depois, a idealidade do grande clínico se torna realidade numa figura inesquecível - o professor Couto. Sábio, mestre, sacerdote. O Sábio-Bom: curar quando puder, aliviar quase sempre, consolar sempre. Tinha grande clínica; os ricos vinham todos ao seu consultório. De um relato de época:

Noite fria, chuvosa, batem à porta:

- O Prof. Couto está?

- Saiu.

- Vai demorar?

- Acredito que sim. Foi à Saúde, atender um paciente - era o bairro pobre, o bairro dos miseráveis, das cabeças de porco.

Meu pai costumava me contar que quando estudante de medicina, chegava bem cedo à enfermaria da Santa Casa. Era uma história muitas vezes repetida: o Prof. Couto chegava muito cedo, era sempre o primeiro a chegar. Um dia me colocou a mão no ombro e disse: vem cá menino, vamos examinar esse doente. Os olhos ficavam sempre cheios de lágrimas.

Aliás era assim, aqui na terra, como lá nos céus. Como Cardarelli na Itália por exemplo.

Mas faltava o cientista. Não havia tradição. Que venha alguém da Europa. De lá vem a resposta. É da mão de Emile Roux. O primeiro sucessor, como Pedro. É textual: Entre o pessoal que tenho a honra de dirigir, ninguem possui mais competencia que o Dr. Oswaldo Cruz cuja capacidade e idoneidade cientificas pessoalmente conheci durante o tempo em que lidou no nosso Instituto.

Falou o papa e ele é infalível. Pelo menos em determinadas circunstâncias. Não se discute.

A Europa se curva ante o Brasil - ou o Brasil ante a Europa: que cada um decida. 
De início é o Barão de Pedro Afonso e Oswaldo. 0 grande cirurgião do Império, e o jovem cientista. Competentes os dois, brilhantes os dois, dedicados os dois - egocêntricos os dois. Não podia dar certo. Sai o Barão, fica Oswaldo, sozinho. Num mesmo reino, não cabem dois senhores.

Oswaldo é fundamentalmente o moderno. Marshal Berman em "Tudo que é sólido desmancha no ar" assim define: "Ser moderno é encontrar-se em um ambiente que promete akentura, poder, alegria, crescimento, autotransformação e transformação das coisas em redor - mas ao mesmo tempo, ameaça destruir tudo o que temos, tudo o que sabemos, tudo o que somos".

A teoria microbiana é o moderno na medicina. É de 1900, ano da fundação do Instituto, o trabalho da Comissão Americana em Cuba - Reed, Carrol, Lazear e Agramonte - demonstrando a partir das idéias de Finlay o mecanismo de transmissão da febre amarela. São modernos os aparelhos que vêm de Manguinhos. Sáo modernas as técnicas usadas. O elevador mais antigo do Rio de Janeiro, ainda em funcionamento, nos leva diariamente à sala da Presidência. Pensou-se em ar refrigerado. Foi chamado o nosso Jacintho de Thormes.

As concep̧̧os que norteiam a orgānizaçáo do Instituto também são modernas.

$\hat{E}$ uma instituiçáo viva, que participa da vida nacional. Dos problemas de Saúde Pública. Na linha de frente. Produção de soros e vacinas - a auto-suficiência hoje tão insisten. temente buscada. Os estudos de quimioterapia - Gaspar Vianna e o tratamento da Leishmaniose - epidemiologia e organização dos serviços, o rural e o urbano, formação de pessoal.

E há também espaço para ciência básica. É de 1907 o trabalho de Henrique Aragão sobre o ciclo evolutivo do Haemoproteus columbae, mostrando pela primeira vez, que um parasito sangüíneo tinha uma fase de evolução nos tecidos. Puro interesse acadêmico. Parasito de pombo. Não servia para nada. Nenhum interesse para o homem. Depois se viu que não era bem assim. Mas isso foi muito depois. E é outra história.

É uma nova maneira de fazer ciência. Não mais o mo. delo antigo, de país atrasado, onde o cientista é um luxo, jarro de porcelana, que sempre exibido aos visitantes não tem utilidade prática.

Assim fora até então. Agora é o esforço de integração de ciência em uma sociedade que já começa a possuir com. plexidade suficiente, para absorver e utilizar os seus resultados. Já se faz desenvolvimento tecnológico.

A decadência de Manguinhos, tem muito a ver com a perda desse impulso inicial para a modernidade - para o futuro. 
É uma volta ao modelo Torre de Marfim desliga do da realidade do país. Sem nenhum demérito faço questão de enfatizar, para o valor acadêmico. Não estou julgando, estou descrevendo. Não me refiro a pessoas, mas à instituição.

E o momento é de modernidade.

Moderno é Pereira Passos, o prefeito que renova a cidade. Repete aqui o que no final de 1850 Haussman, o prefeito de Napoleão III, fez em Paris. Arrasam-se bairros inteiros. Abrem-se largas avenidas. Também a avenida Nevski em Petrogrado é inteiramente reconstituída no início do século XIX. Petrogrado, a cidade símbolo do moderno na Rússia. Janelas para a Europa.

As conseqüências...

Novamente Marshall Bermann:

"Pondo abaixo as velhas e miseráveis habitações medievais, Haussman de maneira involuntária rompeu a crosta do mundo até então hermeticamente selado, da tradicional pobreza urbana... a familia em farrapos do poema beaudele. riano, sai detrás dos detritos para se colocar no centro da cena. O problema não é que eles sejam famintos ou pedintes. $O$ problema é que eles simplesmente não irão embora. Eles também querem um lugar sob a luz..."

E o moderno para se impor, tem que lutar com o arcaico, com a tradição.

Em 1903 Oswaldo assume a Diretoria Geral de Saúde Pública. Combate-se a Peste, a Variola e a Febre Amarela. Combate-se é o termo exato. É luta política, e agressão física também, é a revolta da vacina - armada de baioneta e de navalha. São as críticas nos jornais, é o esforço de ridicularizar através da caricatura. Aragão, companheiro dos primeiros tempos assim se refere: "não era fácil persuadir-se alguém a se submeter a inoculação de pus de vitelo ou soro de cavalo, práticas que mais se afiguravam de magia negra, que de medicina corrente".

Mas Oswaldo é wagneriano. Tem uma dimensão heróica. Entre as proposições de sua tese de doutoramento: " $A$ vehiculação microbiana pelas águas'apresentada à Faculdade de Medicina do Rio de Janeiro em 1892 destaca: a doutrina microbiana nasceu de luta travada entre Pasteur e Pouchet sobre a geração espontânea.

Luta travada. Ele gostava de lutar.

Talvez o seu exito, se devesse a ter incorporado na personalidade complexa e contraditória - humanamente contraditória - um pouco do senhor da Casa Grande, que trazia o látego, na mão que também sabia acariciar, ou que, como se disse de Delmiro Gouveia: "ele batia no corpo, mas năo batia na alma". O sensual do português, que se exacerba de mistura com o índio e o negro. O menino europeu bem educado obediente, mas que adulto no trópico rompe as 
tradições, cria novo espaço. O poeta. As raízes arcaicas, e o novo - ciência ocidental em palácio mourisco. $O$ novo mundo e o velho mundo, no que cada um tinha de melhor - Por isso foi uma sintese bonita. Por isso virou mito.

E se criou então a ciência médica no Brasil. A medicina experimental, que com os irmãos Ozorio de Almeida vai ter também um pouco de Claude Bernard. Novamente a França. Mas a Alemanha também está presente. Na Cruz de Ferro de Rocha Lima, e até nos bigodes à Kaiser.

Aqui também o heróico e o sagrado. Săo claras as palavras de Aragão:

Ninguém se preocupava com sua própria situação incerta ainda em relação aos rumos futuros da Instituição: uma simples dependência da Saúde Pública destituida de qualquer estabilidade e nada mais... Eramos todos jovens e viviamos um momento feliz e absolutamente despreocupado da nossa existência, assim como se fóssemos uns 'enfants de bohême' da ciência, indiferente a nossa instabilidade e satisfeitos com poucos recursos ou mesmo sem eles...

E ainda: ... Ao soar do meio-dia suspendia-se o labor para o almoço na estreita varanda da casinha da fazenda. $A$ mesa estava posta sobre uma meia porta, que se apoiava sobre duas barricas vazias, e era coberta parcialmente, por uma tolha grosseira, havendo dois longos bancos de madeira para os convivas se sentarem. Todos se apressavam porque a comida não era muito abundante: um clássico ensopado de galinha, com batatas, arroz, pão e para terminar algumas bananas e café ralo. Quem se atrasava só encontrava ossos e traços de arroz...

$\mathrm{Na}$ estação do Amorim havia 2 ou 3 cavalos, para Oswaldo e alguém mais categorizado, os outros subiam o morro à pé.

Olímpio da Fonseca nos conta: chegamos tarde para nos matricularmos no curso daquele ano (1912) em que todas as vagas já estavam preenchidas. Desde logo entretanto Oswaldo Cruz prontificou-se a nos fazer inscrever no curso seguinte, de 1913/1914. Imediatamente aceitamos a alternativa...

Fazem-se votos de obediência e de pobreza - de castidade evidentemente não. Afinal de contas, também se educa pelo exemplo.

Havia em tudo uma síntese de brasilidade, tão bem expressa, na relação entre o Dr. Adolpho Lutz e o Joaquim Venâncio. O primeiro protótipo do sábio naturalista à século XIX. Brasileiro, de família suiça-alemã, formação germânica, autoritário, difícil no trato. Durante os trabalhos de campo, quando sentia-se cansado, sentava-se à sombra de uma árvore e declamava Homero, no original. Era muito repousanto - para ele. Venâncio é negro e semi-analfabeto. 
É o auxiliar. $O$ ajudante nos trabalhos de pesquisa. É indispensável, insubstituível. Ao longo dos anos de trabalho, fez sua formação, tornou-se sábio. Foi convida do para trabalhar no estrangeiro. Recusou. Não troco o Joaquim Venâncio por nenhum doutor de Oxford ou de Cambridge, costumava dizer o Dr. Lutz.

Conta-se em Manguinhos, que quando o Rei Alberto veio ao Brasil, fez-se uma comitiva de sábios, para acompanhar a Rainha - naturalista amadora - em passeio pela floresta das redondezas. O Dr. Lutz muito contrafeito é incluído no grupo, e como não havia deixar de ser o Joaquim Venâncio vai junto. $\mathrm{Na}$ hora do almoço, preparam-se as mesas para o pic-nic. Uma para a rainha, as damas e as demais pessoas de estirpe. Outra para os criados. Enfurecidos Lutz protesta:

- Precisamente, ou me sento eu e o Venâncio na mesa de cá, ou eu e o Venâncio na mesa de lä.

$\mathrm{E}$ veio tambémo reconhecimento dos grandes centros. Os prêmios internacionais, veio Stanislas von Prowazek, Giemsa e Hartman e muitos outros...

Mas houve tempo também, para sonhar um castelo das mil e uma noites. Pura poesia, solenidade de cantochão, de mistura com sensualidade moura. Como não ser sensual quando se tem sangue português e ainda por cima se vive nos trópicos. Os cardeais da clínica já pontificavam: No Brasil é preciso pensar sifiliticamente.

Poesia em pedra, em argamassa, em tijolos de Marseille, em azulejos portugueses, em louça inglesa. $E$ a quatro mãos. Com um mestre de obras português. Dos bons; como meu bisavô. E sem verba. Ou melhor, com verba desviada do Serviço de Saúde Pública. Sem permissão das autoridades competentes. E a grandes custos - tudo caro. Desvio de fundos públicos. Afinal de contas, uma síntese do que havia de melhor d'além e d'aquém mar.

E hoje em dia como é difícil, e custa caro restaurar.

Mas a doença já o vem consumindo aos poucos. 0 desgaste físico é notório. Nada mais que um regular fenômeno biológico, dirá ele. Há qualquer coisa do Dr. Fausto, de Thomas Mann.

Em 1915 um prêmio de consolação. Provavelmente muito amargo. Sabe a fel. Vai ser o Prefeito de Petrópolis. Apesar de tudo a poesia das hortências; morre entre elas em 11 de fevereiro de 1917. 